Eur. J. Clin. Chem. Clin. Biochem.

Vol. 31, 1993, pp. 59-68

(C) 1993 Walter de Gruyter \& Co.

Berlin - New York

\title{
Acetylation Phenotypes and Biological Variation in a French Caucasian Population
}

\author{
By Z. Braz Vieira da Silva Pontes ${ }^{1}$, M. Vincent-Viry ${ }^{1}$, R. Gueguen ${ }^{1}, M$. M. Galteau ${ }^{1,2}$ and G. Siest ${ }^{1,2}$ \\ 1 Centre de Médecine Préventive, Vandoeuvre-les-Nancy, France \\ 2 Centre du Médicament, URA CNRS No 597, Nancy, France
}

(Received July 2/November 2, 1992)

Summary: Factors affecting the caffeine acetylation phenotype were investigated in a French Caucasian population of 150 unrelated supposedly healthy subjects, aged 18 to 63 years. This population, including 75 men and 75 women, was used to determine whether the acetylation polymorphism is related to environmental influences such as smoking habits, intake of alcohol, use of oral contraceptives, use of certain drugs. The acetylation phenotype was assessed from the molar ratio of two caffeine metabolites: 5-acetylamino-6formylamino-3-methyluracil/1-methylxanthine. For values less than 0.85 , the subjects were classified as poor acetylators (frequency, $\overline{\mathrm{x}} \pm \mathrm{SD}: 61.3 \pm 7.9 \%$ ) in this study. Dose recoveries of 5-acetylamino-6-formylamino3-methyluracil $(\overline{\mathrm{x}} \pm \mathrm{SD})$ were $1.26 \pm 0.85 \%$ and $3.58 \pm 1.64 \%$ in slow and rapid acetylators, respectively. The recovery $(\overline{\mathrm{x}} \pm \mathrm{SD})$ of 1 -methylxanthine in the 3 hour-urine was $2.86 \pm 1.51 \%$ in slow acetylators and $2.36 \pm 1.27 \%$ in rapid acetylators. The mean value (and SD) of the molar ratio was $0.437(0.177)$ and 1.669 $(0.651)$ for slow and rapid acetylators. Three other metabolite ratios can also provide an acetylation index: 5-acetylamino-6-formylamino-3-methyluracil/5-acetylamino-6-formylamino-3-methyluracil + 1-methylxanthine + 1-methyluric acid; 5-acetylamino-6-formylamino-3-methyluracil/1-methylxanthine + 1-methyluric acid + 1,7-dimethyluric acid; and 5-acetylamino-6-formylamino-3-methyluracil/1-methylxanthine + 1-methyluric acid + 1,7-dimethyluric acid + 1,7-dimethylxanthine with a bimodal distribution for the former and a trimodal distribution for the two latter ratios, both showing about $95 \%$ concordance with the 5-acetylamino6-formylamino-3-methyluracil/1-methylxanthine ratio. Age did not influence the excretion of caffeine and its five major metabolites. A marked influence of sex was observed only on the unchanged caffeine excretion, and the effect was greater in slow acetylators than in rapid acetylators. The 5-acetylamino-6-formylamino-3methyluracil excretion was about three times higher in rapid acetylators than in slow acetylators in both sexes.

\section{Introduction}

Caffeine or 1,3,7-trimethylxanthine is a very common substance (present in coffee, tea, chocolate, coca-cola, etc.). This compound (like isoniazid, sulphadimidine, or dapsone) can be used for determining the acetylation phenotype $(1-5)$, and some authors have used it to assess genotypes (6). In man, the metabolism of caffeine is rather complicated and follows different pathways:

- successive oxidations by cytochrome P-450-dependent $\mathrm{N}$-demethylases, giving first 1,7-dimethylxanthine, then 1,7-dimethyluric acid by the action of the cytochrome P-450-dependent 8-hydroxylase. 1,7-dimethylxanthine can be further metabolized to an unstable intermediate.

- transformation of this unknown metabolite by polymorphic $\mathrm{N}$-acetyltransferase, leading to a major acetylated metabolite: 5-acetylamino-6-formylamino-3-methyluracil. Alternatively, $\mathrm{N}$-demethylation of 1,7-dimethylxanthine produces 1methylxanthine which is converted by xanthine oxidase into the hydroxylated metabolite, 1-methyluric acid.

Eur. J. Clin. Chem. Clin. Biochem. / Vol. 31, 1993 / No. 2 
Interindividual genetically based variations in the acetylation pathway of caffeine have been described in humans (6-8) and ethnic differences have also been reported (9).

The classification of subjects into slow or rapid acetylators depends on the urinary excretion ratio (5-acetylamino-6-formylamino-3-methyluracil/1-methylxanthine) determined on urine collected during the 3 hours following oral ingestion of caffeine. The slow acetylator trait is transmitted as a recessive or codominant autosomal trait $(10-12,13)$ and is linked with a defective production by the gene of the hepatic Nacetyltransferase (14). Using caffeine as the test substance, some authors observed two populations in the rapid acetylator group, comprising heterozygous and homozygous subjects $(6,15,16)$.

Several protocols based on the use of caffeine as the metabolic substrate have been proposed in the literature for determining the three phenotypes. However, the administered dose, the urinary collection time and the necessity for a diet without xanthines have been differently reported $(6,12,16)$. In the present work, after modifying the HPLC method previously described by Grant $(12,15)$, the acetylation phenotype was explored in a population of 150 unrelated healthy subjects. The effects of age, sex, use of tobacco, alcohol intake and use of oral contraceptives were studied on the urinary excretion of the different metabolites. In addition, relationships were investigated between blood constituents (cholesterol, triacylglycerols and glucose) and the urinary excretion of metabolites.

\section{Materials and Methods}

Samples

Blood specimens were collected into Vacutainer Tubes (Becton Dickinson, Rutherford, NJ) by venipuncture from the cubital vein of supine fasting subjects. The samples were promptly centrifuged for $5 \mathrm{~min}$ at $3000 \mathrm{~g}$.

Urine samples were collected over the $3-\mathrm{h}$ period immediately following ingestion of the test substance.

\section{Chromatographic conditions}

The urinary concentrations of 5-acetylamino-6-formylamino-3methyluracil, 1-methylxanthine, 1-methyluric acid, 1,7-dimethylxanthine, 1,7-dimethyluric acid and of unchanged caffeine (1,3,7-trimethylxanthine) were determined by an HPLC method previously described by Grant et al. $(12,15)$ and modified in our laboratory. The HPLC system consisted of a one solvent delivery pump (Model 6000 A, Waters Associates, Milford, MA, USA), a refrigerated auto-injector (Model As-48, BioRad, Richmond, CA, USA), a UV-visible variable-wavelength detector (Model 481, Waters) and an integrator (Model CR3A, Shimadzu, Roucaire, Velizy-Villacoublay, France). The system was operated at room temperature.
The analytical column was prepacked with Ultraspher ODS, ( $5 \mu \mathrm{m}$ particle size, $150 \mathrm{~mm} \times 4.6 \mathrm{~mm}$, Beckman, Paris, France) and the guard column with LiChrospher $100 \mathrm{RP} 18(5 \mu \mathrm{m}$ particle size, Hibar LiChrocart, Merak-Clevenot, Nogent-surMarne, France).

The mobile phase was a mixture of acetic acid $0.5 \mathrm{~g} / \mathrm{l}$, volume fraction 0.12 in methanol. It was filtered through a $0.45 \mu \mathrm{m}$ HV type microfilter (Millipore, Waters Associates) and used at a flow-rate of $1.0 \mathrm{ml} / \mathrm{min}$.

Twenty $\mu$ l of the urinary sample were automatically injected into the HPLC system through a six-way injection valve (Rheodyne 7000 , Cotati, CA, USA). The UV detection was performed at $280 \mathrm{~nm}$.

\section{Preparation of the urinary samples}

Two hundred $\mu$ internal standard $(\mathrm{N}$-acetyl-4-aminophenol: $120 \mathrm{~g} / \mathrm{l}$ in chloroform, $794 \mathrm{mmol} / \mathrm{l}$ ) were placed in a glass tube and evaporated to dryness under a stream of nitrogen (pressure, 200 bars). To the dried residue were added $200 \mu \mathrm{l}$ bidistilled water, $120 \mathrm{mg}$ ammonium sulphate and $8 \mathrm{ml}$ chloroform-isopropanol mixture $(85+15$ by vol.) The mixture was then vortexed for 2 minutes and centrifuged for 5 minutes at 2000 $\min ^{-1}$.

The aqueous phase was discarded. The chloroformic phase (about $7 \mathrm{ml}$ ) was transferred to another glass-tube and evaporated at $40-45^{\circ} \mathrm{C}$ under a stream of nitrogen. The resulting dried sample was stoppered and frozen at $-20^{\circ} \mathrm{C}$ until analysis. Just before analysis, the dried residue was dissolved into $1 \mathrm{ml}$ mobile phase and $20 \mu \mathrm{l}$ of this solution were injected into the HPLC system.

\section{Preparation of the standard solutions}

The following standard solutions were prepared for the establishment of calibration curves: 1-methylxanthine (0.482 $\mathrm{mmol} / \mathrm{l}), 1,7$-dimethylxanthine $(0.444 \mathrm{mmol} / \mathrm{l})$ plus 5 -acetylamino-6-formylamino-3-methyluracil $(0.222 \mathrm{mmol} / \mathrm{l})$ or 1 -methyluric acid $(0.275 \mathrm{mmol} / \mathrm{l})$ plus 1,7-dimethyluric acid $(0.408$ $\mathrm{mmol} / \mathrm{l})$.

A $0.08 \mathrm{~mol} / 1$ tetraborate disodium buffer adjusted to $\mathrm{pH} 7$ with $1 \mathrm{~mol} / \mathrm{l}$ phosphoric acid was used to dissolve the 1 -methyluric acid.

\section{Quantification of the metabolites}

Values were expressed per litre of urine. The calibration curves were established each day covering the range 0 to $221 \mu \mathrm{mol} / \mathrm{l}$ for 5-acetylamino-6-formylamino-3-methyluracil, .0 to 275 $\mu \mathrm{mol} / \mathrm{l}$ for 1 -methyluric acid, 0 to $482 \mu \mathrm{mol} / 1$ for 1 -methylxanthine, 0 to $444 \mu \mathrm{mol} / \mathrm{l}$ for 1,7-dimethylxanthine, 0 to $408 \mu \mathrm{mol} / \mathrm{l}$ for 1,7-dimethyluric acid and 0 to $412 \mu \mathrm{mol} / 1$ for 1,3,7-trimethylxanthine. Every tube was spiked with internal standard (Nacetyl-4-aminophenol, $0.794 \mathrm{mmol} / 1$ final concentration), and if necessary with caffeine $(0.412 \mathrm{mmol} / \mathrm{l})$.

\section{Statistics}

An iterative method of fuzzy sets described by Schroeder (17) was used to determine whether the population could be a mixture of different Gaussian subpopulations, and to calculate, if necessary, the optimal limits of separation of the subpopu-
lations.

Multiple regression analysis was used to evaluate possible correlations between the different metabolites measured and age, sex, and certain blood constituents. The concentration of sig- 
nificance was determined by the F-value at $\mathrm{p}<0.001$ (10.83). Student's t-test, Welsh and Fischer-Snedecor tests were also used.

\section{Phenotyping}

Adult subjects ( $>18$ years) took one capsule containing 0.772 $\mu \mathrm{mol}(150 \mathrm{mg})$ caffeine monohydrate (Coopération Pharmaceutique Française, Melun, France), and they collected their urine during the following 3 hours. Urine sample volumes and $\mathrm{pHs}$ were measured. Urines were aliquoted, extracted and stored at $-20^{\circ} \mathrm{C}$ until analysis. The urinary pHs must be in the range of 5.0 to 6.5 . If not, urines were discarded.

Acetylation phenotype was assigned by using the molar ratio of 5-acetylamino-6-formylamino-3-methyluracil and 1-methylxanthine excreted during 3 hours:

molar ratio $=$

5-acetylamino-6-formylamino-3-methyluracil ( $3 \mathrm{~h}$ urine) 1-methylxanthine ( $3 \mathrm{~h}$ urine)

\section{Human population}

The study was performed at the Centre for Preventive Medicine of Vandœuvre-les-Nancy (France). Healthy unrelated volunteers $(n=150)$ participated in the study which was approved by the Ethics Committee of Nancy. These 18-to-63 year-old subjects, 75 men and 75 women (married couples), were fasting when attending the Centre for Preventive Medicine for a health examination (18).

Each subject was classified as a slow or rapid acetylator, according to whether the value of the molar 5-acetylamino-6formylamino-3-methyluracil/1-methylxanthine ratio was $<0.85$ or $>0.85$, respectively. Subjects under treatment with drugs known to inhibit or to interfere with the acetylation phenotype were eliminated from the study. A comparison with three other acetylation metabolic ratios was performed:

5-acetylamino-6-formylamino-3-methyluracil/5-acetylamino-6formylamino-3-methyluracil +1 -methylxanthine +1 -methyluric acid; 5-acetylamino-6-formylamino-3-methyluracil/ 1-methylxanthine +1 -methyluric acid + 1,7-dimethyluric acid; and 5-acetylamino-6-formylamino-3-methyluracil/1-methylxanthine +1 -methyluric acid $+1,7$-dimethylxanthine $+1,7-$ dimethyluric acid.

\section{Results}

\section{Analytical variations}

Calibration curves are linear for 5-acetylamino-6-formylamino-3-methyluracil up to $221 \mu \mathrm{mol} / \mathrm{l}(\mathrm{r}=1.00)$; for 1-methylxanthine, 1,7-dimethylxanthine and 1,7dimethyluric acid up to $482,444,408 \mu \mathrm{mol} / 1$ $(r=1.00)$; for 1-methyluric acid up to $275 \mu \mathrm{mol} / 1$ $(r=1.00)$ and for 1,3,7-trimethylxanthine up to 412 $\mu \mathrm{mol} / \mathrm{l}(\mathrm{r}=1.00)$. Inter-day coefficients of variation are $3.8 \%$ for 5-acetylamino-6-formylamino-3-methyluracil; $5.2 \%$ for 1 -methyluric acid; $7.6 \%$ for 1 -methylxanthine; $12.0 \%$ for 1,7 -dimethyluric acid; $9.3 \%$ for 1,7-dimethylxanthine; and $11.1 \%$ for $1,3,7$-trimethylxanthine. Coefficients of variation for repeatability usually do not exceed $4.1 \%$ except for 1-methylxanthine (7.1\%) and 1,3,7-trimethylxanthine (9.2\%). Conditions for the storage of 5-acetylamino-6-for- mylamino-3-methyluracil and 1-methylxanthine were published earlier (18). After 35 days storage at $+4^{\circ} \mathrm{C}$ or $-20^{\circ} \mathrm{C}$, 5-acetylamino-6-formylamino-3-methyluracil decreased by $10 \%$ or $15 \%$, respectively. 1 Methylxanthine and 1-methyluric acid decreased by $10 \%$ whatever the temperature. But 1,7-dimethyluric acid and 1,7-dimethylxanthine decreased by $50 \%$ after 35 days and $20 \%$ after 15 days at $+4^{\circ} \mathrm{C}$ or $-20^{\circ} \mathrm{C}$. The analysis of the different metabolites must be performed in the fifteen days following urine collection.

\section{Descriptive analysis of the population}

The structure of the population is shown in table 1 , and the frequency distribution histograms of the four ratios suggest two or three separate phenotypic populations (fig. 1). These distributions can be modelled as a mixture of two Gaussian subpopulations representing slow and rapid acetylators (but not from the 5-acetylamino-6-formylamino-3-methyluracil/5-acetylamino-6-formylamino-3-methyluracil + 1-methylxanthine +1 -methyluric acid ratio), or as a mixture of three Gaussian subpopulations representing homozygous slow acetylators, heterozygous and homozygous rapid acetylators, based on the 5-acetylamino6-formylamino-3-methyluracil/1-methylxanthine and 5-acetylamino-6-formylamino-3-methyluracil/1-methylxanthine +1 -methyluric acid $+1,7$-dimethyluric acid ratios. Antimodes were statistically determined at 0.85 and 2.80 for the 5-acetylamino-6-formylamino-3-methyluracil/1-methylxanthine ratio and at 0.29 and 0.58 for the 5-acetylamino-6-formylamino-3methyluracil/1-methylxanthine +1 -methyluric acid $+1,7$-dimethyluric acid ratio.

Tab. 1. Caffeine acetylation in a Caucasian population. No. (and \%)

\begin{tabular}{|c|c|c|c|c|c|}
\hline & \multirow{2}{*}{$\mathrm{N}$} & \multicolumn{2}{|c|}{ Slow acetylators } & \multicolumn{2}{|c|}{ Rapid acetylators } \\
\hline & & Absolute & $\%$ & Absolute & $\%$ \\
\hline All subjects & 150 & 92 & 61.3 & 58 & 38.7 \\
\hline Men & 75 & 42 & 56.0 & 33 & 44.0 \\
\hline Women & 75 & 50 & 55.7 & 25 & 33.3 \\
\hline
\end{tabular}

$\chi^{2}=1.78 \quad \mathrm{p}=0.18$ (NS)

\section{Variations according to age and sex}

Age did not influence the excretions of caffeine and of its five major metabolites. But there is an influence of sex, especially on the 1,3,7-trimethylxanthine excretion, which is more significant in slow acetylators than in rapid acetylators (tab. 2). Hovvever, the 5- 

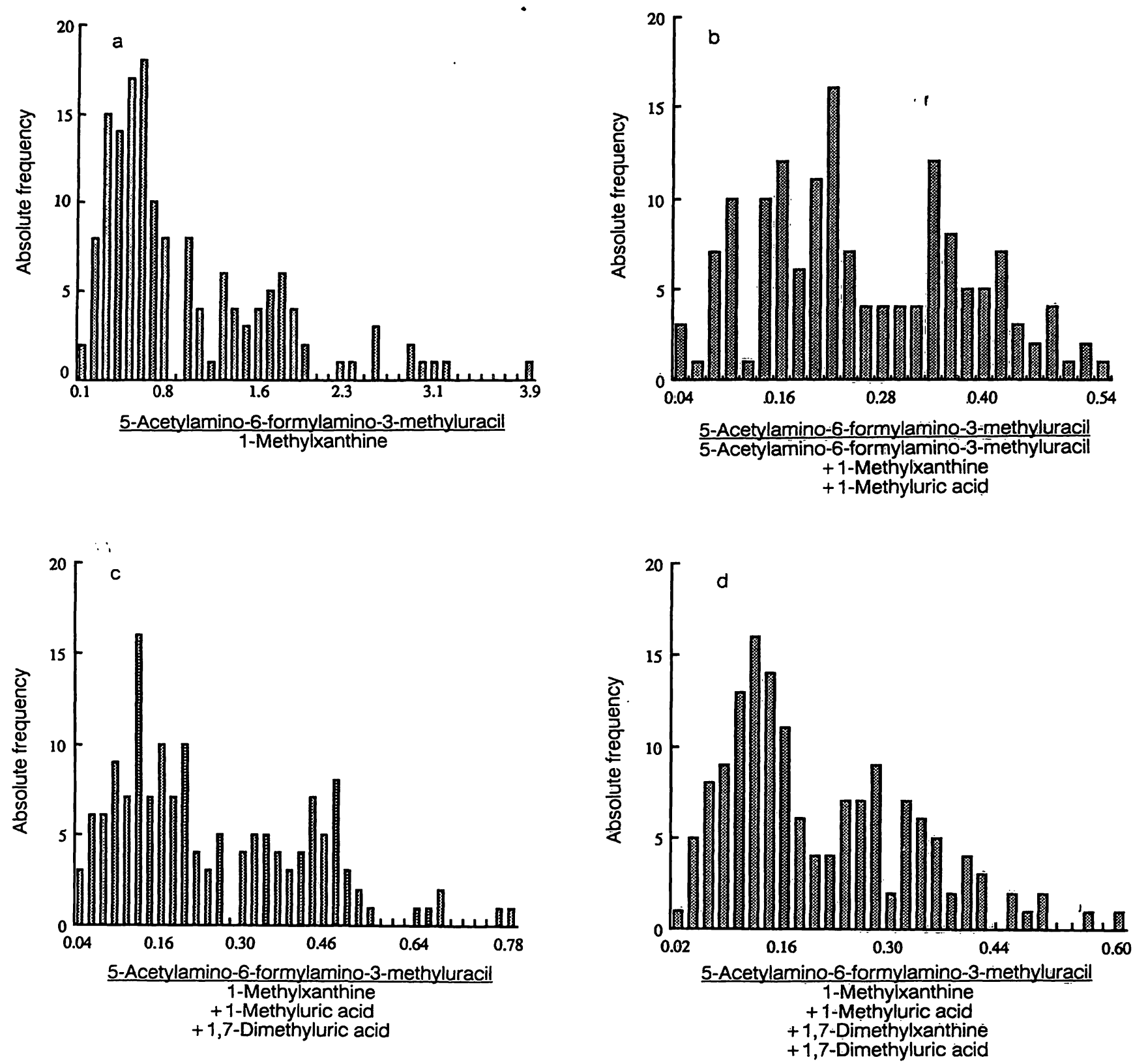

Fig. 1. Frequency distributions of the 5-acetylamino-6-formylamino-3-methyluracil/1-methylxanthine ratio and of three other caffeine metabolite ratios in 150 healthy unrelated Caucasian volunteers.

acetylamino-6-formylamino-3-methyluracil excretion was lower in women than men in the rapid acetylator group. $56.0 \%$ of the men and $66.7 \%$ of the women were slow acetylators of caffeine (tab. 1).

\section{Effect of drugs and xenobiotics}

\section{Drugs (oestrogens, progestative and oral contraceptive drugs)}

Five women were taking oestrogens, 7 used progestative drugs and 6 were taking oral contraceptives. When these volunteers were considered as a group, it was shown that the drugs in question did not modify the excretion of caffeine and its five metabolites.

\section{Xenobiotics}

Tobacco and alcohol consumption did not change the excretion of 5-acetylamino-6-formylamino-3-methyluracil and 1-methylxanthine and did not affect the molar ratio 5-acetylamino-6-formylamino-3-methyluracil/1-methylxanthine, thus allowing the unambiguous assignment of the acetylation phenotype. None. of the caffeine metabolites was significantly correlated with tobacco or alcohol intake among the slow acetylator phenotype. We observed a slight correlation $(r=0.198)$ between 1,3,7-trimethylxanthine and alcohol in slow acetylators, $-0,265$ in rapid acetylators, and with tobacco $(-0.197)$ in slow acetylators. These correlations were very close to the limits of significance. 
Tab. 2. Urinary excretions of caffeine and five of its metabolites ( $3 \mathrm{~h}$ urine) for slow and rapid acetylators: comparison by sex ${ }^{\mathrm{a}}$ )

Men Women Student

t-test

Slow acetylators

$\mathrm{N}$

5-Acetylamino-6-formylamino-3-methyluracil

1-Methyluric acid

$1.40(0.86)$

$4.29 \quad(3.42)$

3.07 (1.59)

$2.22(1.80)$

$2.42(2.22)$

$0.71 \quad(0.53)$

14.1

$0.457(0.188)$

1,7-Dimethyluric acid

1,3,7-Trimethylxanthine

Total

5-Acetylamino-6-formylamino-3-methyluracil/ 1-methylxanthine

Rapid acetylators

$\mathrm{N}$

5-Acetylamino-6-formylamino-3-methyluracil

1-Methyluric acid

1-Methylxanthine

1,7-Dimethyluric acid

1,7-Dimethylxanthine

1,3,7-Trimethylxanthine

Total

5-Acetylamino-6-formylamino-3-methyluracil/

1 -methylxanthine
50

$1.13(0.83)$

$3.37(2.38)$

$2.68 \quad(1.42)$

$2.08 \quad(1.85)$

$2.46(1.73)$

$1.31 \quad(0.92)$

13.0

$0.420(0.167)$

N.S. ${ }^{b}$ )

N.S.

N.S.

N.S.

N.S.

***

N.S.

a) Results are percentages (mean (and SD)) of caffeine ingested

b) N.S.: Not significant

$* * *=p<0.001$

$* *=\mathrm{p}<0.01$

$*=\mathrm{p}<0.05$

\section{Biological variations}

We observed, among adults, a slight correlation between the concentration of blood glucose and the urinary excretions of 5-acetylamino-6-formylamino3-methyluracil, 1-methyluric acid and 1,3,7-trimethylxanthine $(r=0.275,0.298$ and 0.193 , respectively, with a threshold value $|r|=0.165$ ). In the group of slow acetylators, the 5-acetylamino-6-formylamino-3methyluracil/1-methylxanthine ratio was positively correlated with the glucose concentration $(r=0.255$; $|r|=0.210$ ). In the group of rapid acetylators, the glucose concentration was highly correlated with 5acetylamino-6-formylamino-3-methyluracil or 1,3,7trimethylxanthine $(r=0.349 ; 0.327 ;|r|=0.270)$. Adjustment of glucose concentration on the sex and Quetelet index (weight per squared height $\left(\mathrm{g} / \mathrm{m}^{2}\right)$ ) did not significantly increase these correlations within the rapid acetylator group. Triacylglycerols and cholesterol concentrations showed no correlation with either caffeine metabolites or the 5-acetylamino-6-formylamino-3-methyluracil/1-methylxanthine ratio.

\section{Determination of the acetylation phenotype}

Using the molar 5-acetylamino-6-formylamino-3methyluracil/1-methylxanthine ratio as an index of

the polymorphic $\mathrm{N}$-acetyltransferase activity, the frequency of the slow acetylator trait was determined. The distribution of the molar metabolite ratio shows slow acetylators $(n=92)$ with values between 0 and 0.85 ; rapid acetylators $(n=58)$ with values between 0.90 and 3.90. This latter sub-group could be divided into heterozygous and homozygous rapid acetylators, i.e. the frequency distribution of the urinary molar ratio of 5-acetylamino-6-formylamino-3-methyluracil/1-methylxanthine was trimodal. The cut-off value for separation of heterozygous and homozygous rapid acetylators was 2.80 using the method of fuzzy-sets (17). Six subjects were rapid homozygous acetylators. Total dose recoveries of 5-acetylamino-6-formylam= ino-3-methyluracil and 1-methylxanthine as percentage of the ingested caffeine dose were $4.1 \%$ and $5.9 \%$ in slow acetylators and in rapid acetylators, respectively, with a great difference in the 5-acetylamino-6formylamino-3-methyluracil excretion of slow and rapid acetylators $(p<0.001)$, and a smaller difference in the 1-methylxanthine excretion $(p<0.05)$. 5-Acetylamino-6-formylamino-3-methyluracil excretion was lower and 1-methylxanthine excretion higher in slow acetylators than in rapid acetylators (tab. 3). Mean dose recoveries (metabolite in \% of ingested caffeine dose) of 1-methyluric acid, 1,7-dimethyluric 
Tab. 3. Urinary excretions ( $3 \mathrm{~h}$ urine) of 5-acetylamino-6-formylamino-3-methyluracil, 1-methyluric acid, 1-methylxanthine, 1,7-dimethyluric acid, 1,7-dimethylxanthine, 1,3,7-trimethylxanthine after oral ingestion of 150 $\mathrm{mg}$ caffeine (i. e. $0.772 \mathrm{mmol}$ ). Results are given as mean (SD)

\begin{tabular}{llll}
\hline & $\begin{array}{l}\text { Slow } \\
\text { acetylators }\end{array}$ & $\begin{array}{l}\text { Rapid } \\
\text { acetylators }\end{array}$ & $\begin{array}{l}\text { Student } \\
\text { t-test }\end{array}$ \\
92 & 58 & \\
\hline
\end{tabular}

5-Acetylamino-6-formylamino-3-methyluracil

$\begin{array}{lrrrrr}\mu \mathrm{mol} / 3 \mathrm{~h} & 9.69 & (6.56) & 27.62 & (12.69) & \mathrm{p}<0.001 \\ \text { Recovery, \%*) } & 1.26 & (0.85) & 3.58 & (1.64) & \mathrm{p}<0.001\end{array}$

1-Methyluric acid

$\mu \mathrm{mol} / 3 \mathrm{~h} \quad 29.27(22.54) \quad 29.94(20.29) \quad$ N.S.

Recovery, \%*) 3.79 (2.92) 3.88 (2.63) N.S.

1-Methylxanthine

$\begin{array}{lrrrll}\mu \mathrm{mol} / 3 \mathrm{~h} & 22.08(11.63) & 18.19 & (9.83) & \text { N.S. } \\ \text { Recovery, \%*) } & 2.86(1.51) & 2.36 & (1.27) & \mathrm{p}<0.05\end{array}$

1,7-Dimethyluric acid

$\begin{array}{lrrrr}\mu \mathrm{mol} / 3 \mathrm{~h} & 16.59(14.00) & 19.33(11.62) & \text { N.S. } \\ \text { Recovery, \%*) } & 2.14(1.82) & 2.50 & (1.50) & \text { N.S. }\end{array}$

1,7-Dimethylxanthine

$\mu \mathrm{mol} / 3 \mathrm{~h} \quad 18.85(15.09) \quad 20.56(11.92) \quad$ N.S.

Recovery, \%*) 2.44 (1.95) 2.66 (1.54) N.S.

1,3,7-Trimethylxanthine

$\mu \mathrm{mol} / 3 \mathrm{~h} \quad 8.00 \quad(6.32) \quad 9.72 \quad(8.59) \quad$ N.S.

Recovery, \%*) $1.04(0.82) \quad 1.26 \quad(1.11) \quad$ N.S.

Ratio 5-acetylamino-6-formylamino-3-methyluracil/1-methylxanthine

$\begin{array}{lllll}\mu \mathrm{mol} / \mu \mathrm{mol} & 0.437(0.177) & 1.669(0.651) & \mathrm{p}<0.001 \\ \mathrm{Log}- & 0.940(0.508) & 0.447(0.356) & \mathrm{p}<0.001\end{array}$

Log $-0.940(0.508) \quad 0.447(0.356) \quad \mathrm{p}<0.001$

*) Substance, fraction of caffeine ingested

acid, 1,7-dimethylxanthine and 1,3,7-trimethylxanthine were similar between the two phenotypes. The 3-h urine excretion of these 3 metabolites and of unchanged caffeine was $9.4 \%$ and $10.3 \%$, respectively, for slow and rapid acetylators, and the total mean values of urinary outputs of the five major metabolites of caffeine and of native caffeine was $13.67 \%$ for the slow acetylator phenotype and $16.25 \%$ for the rapid acetylator phenotype (tab. 3), corresponding to $105.5 \mu \mathrm{mol}(19.6 \mathrm{mg})$ and 125.4 $\mu \mathrm{mol}(24.1 \mathrm{mg})$ for slow and rapid acetylators. Mean values (and SD) for the 5-acetylamino-6-formylamino-3-methyluracil/1-methylxanthine ratio were $0.437(0.177)$ and $1.669(0.651)$ for the slow and rapid acetylators.

Among the studied population, $61.3 \%$ of the subjects were classified as slow acetylators and $38.7 \%$ as rapid acetylators, accepting that such a classification corresponds to the properties of a major locus with two codominant alleles, as suggested by Butler et al. (13) and Vincent-Viry et al. (20). The frequency of the slow acetylator allele was estimated to be 0.783 and that of the rapid acetylator allele 0.217 . The expected genotypic frequencies, calculated according to the Hardy-Weinberg law, were: homozygous slow acetylators SS $\left(\mathrm{q}^{2}\right)$ 0.613; heterozygous rapid acetylators SR (2 pq) 0.340; homozygous rapid acetylators $\mathrm{RR}\left(\mathrm{p}^{2}\right)$ 0.047. Further studies must be done using segregation analysis to elucidate this point. For the ratios 5-acetylamino-6-formylamino-3-methyluracil/ 1-methylxanthine +1 -methyluric acid $+1,7$-dimethyluric acid and 5-acetylamino-6-formylamino-3methyluracil/1-methylxanthine +1 -methyluric acid $+1,7$-dimethylxanthine $+1,7$-dimethyluric acid, the cut-off values for assignment of phenotype were respectively 0.29 and 0.22 with $94.7 \%$ and $94.0 \%$ of concordance between these two ratios and the 5-acetylamino-6-formylamino-3-methyluracil/1-methylxanthine ratio. The first ratio identified $59 \%$ as slow acetylators and $41 \%$ as rapid acetylators, the second ratio $58.7 \%$ as slow acetylators and $41.3 \%$ as rapid acetylators.

The allelic frequencies for the allele controlling the slow acetylator trait were 0.768 and 0.766 , based on the 5-acetylamino-6-formylamino-3-methyluracil/1methylxanthine +1 -methyluric acid $+1,7$-dimethyluric acid and 5-acetylamino-6-formylamino-3-methyluracil/1-methylxanthine +1 -methyluric acid $+1,7-$ dimethylxanthine +1 ,7-dimethyluric acid ratios, respectively. These results were very close to the proportions of slow and rapid acetylators found with 5acetylamino-6-formylamino-3-methyluracil/1-methylxanthine ratio.

\section{Pedigree analysis}

In order to support the hypothesis that the acetylation phenotype is the result of a codominant transmission of the alleles, we examined the 75 nuclear families of the 75 couples used to study the 5-acetylamino6-formylamino-3-methyluracil/1-methylxanthine and 5-acetylamino-6-formylamino-3-methyluracil/1-methylxanthine +1 -methyluric acid +1 ,7-dimethyluric acid urinary ratios. If the acetylation capabilities described by these ratios were inherited by Mendelian transmission, the observed phenotypes of children must correspond to those expected by classical Mendelian segregation (tab. 4). Chi-square tests, not significant for the two ratios, proved the similarities between observed values and those expected by classical Mendelian segregation. However, table 4 shows that the use of the cut-off values given by the method of fuzzy-sets led to the wrong classification of two children (5-acetylamino-6-formylamino-3-methylura- 
Tab. 4. Observed matings and resulting phenotypes of offspring compared with expected values

\begin{tabular}{|c|c|c|c|c|c|c|c|c|}
\hline \multirow[t]{3}{*}{ Matings } & \multirow{3}{*}{$\begin{array}{l}\text { Number of } \\
\text { matings }\end{array}$} & \multirow{3}{*}{$\begin{array}{l}\text { Number of } \\
\text { children }\end{array}$} & \multicolumn{6}{|c|}{ Offspring } \\
\hline & & & \multicolumn{3}{|c|}{ Observed phenotypes } & \multicolumn{3}{|c|}{ Expected phenotypes } \\
\hline & & & SS & RS & $\mathbf{R R}$ & SS & RS & RR \\
\hline \multicolumn{9}{|c|}{ a) 5-Acetylamino-6-formylamino-3-methyluracil/1-methylxanthine ratio } \\
\hline $\mathrm{RS} \times \mathrm{SS}$ & 38 & 70 & 31 & 39 & 0 & 35.0 & 35.0 & 0 \\
\hline SS $\times$ SS & 26 & 42 & 42 & 0 & 0 & 42.0 & 0 & 0 \\
\hline $\mathrm{RS} \times \mathrm{RS}$ & 6 & 10 & 5 & 5 & 0 & 2.5 & 5.0 & 2.5 \\
\hline $\mathrm{RS} \times \mathrm{RR}$ & 2 & 5 & $1^{*}$ & 4 & 0 & 0 & 2.5 & 2.5 \\
\hline $\mathrm{RR} \times \mathrm{SS}$ & 2 & 2 & $1 *$ & 1 & 0 & 0 & 2.0 & 0 \\
\hline $\mathrm{RR} \times \mathrm{RR}$ & 1 & 2 & 0 & 0 & 2 & 0 & 0 & 2.0 \\
\hline Total & 75 & 131 & 80 & 49 & 2 & 79.5 & 44.5 & 7.0 \\
\hline
\end{tabular}

$\chi^{2}=4.03, \mathrm{p}<0.10 \mathrm{NS}$

b) 5-Acetylamino-6-formylamino-3-methyluracil/1-methylxanthine + 1-methyluric acid + 1,7-dimethyluric acid ratio

\begin{tabular}{|c|c|c|c|c|c|c|c|c|}
\hline $\mathrm{RS} \times \mathrm{SS}$ & 37 & 65 & 30 & 31 & $4^{*}$ & 32.5 & 32.5 & 0 \\
\hline$S S \times S S$ & 27 & 46 & 44 & $2^{*}$ & 0 & 46.0 & 0 & 0 \\
\hline $\mathrm{RS} \times \mathrm{RS}$ & 6 & 10 & 5 & 5 & 0 & 2.5 & 5 & 2.5 \\
\hline $\mathrm{RS} \times \mathrm{RR}$ & 2 & 5 & $1 *$ & 3 & 1 & 0 & 2.5 & 2.5 \\
\hline$R R \times S S$ & 2 & 3 & $1^{*}$ & 2 & 0 & 0 & 3.0 & 0 \\
\hline $\mathrm{RR} \times \mathrm{RR}$ & 1 & 2 & 0 & 0 & 2 & 0 & 0 & 2.0 \\
\hline Total & 75 & 131 & 81 & 43 & 7 & 81.0 & 43.0 & 7.0 \\
\hline
\end{tabular}

$\chi^{2}=0 \rightarrow<0.211, \mathrm{p}>0.90 \mathrm{NS}$

The cut-off values used to divide the population into slow (SS) and rapid (RR, RS) acetylators were statistically determined by the method of fuzzy-sets i.e. 0.85 and 2.80 for a) and 0.29 and 0.58 for b) (16).

* misclassified

cil/1-methylxanthine) and eight children (5-acetylamino-6-formylamino-3-methyluracil/1-methylxanthine +1 -methyluric acid + 1,7-dimethyluric acid). In addition, the two types of assessment of the acetylation phenotype gave different results for 11 genotypic matings.

\section{Discussion}

Acetylation polymorphism in bumans is the result of a different expression of the activity of the human liver $\mathrm{N}$-acetyltransferase. The slow acetylation capacity was found to be associated with a decrease in the quantity of immunodetectable $\mathrm{N}$-acetyltransferase protein in liver cytosol (14). A cDNA for the polymorphic $\mathrm{N}$-acetyltransferase (NAT) was used by Blum et al. (21) in a restriction mapping, which identified three non-overlapping clusters called NAT1, NAT2 and NATP.

Assuming that these enzyme activities are responsible for the acetylation polymorphism, it is possible that their activities are affected by various biological conditions e.g. age, sex, overweight or environmental influences such as tobacco or alcohol intake, thereby modifying the expression of the phenotype.

The total excretion of caffeine and its metabolites seemed to be higher in men than in women (tab. 2).
This result is in agreement with that of Griffiths et al. (22) who suggested that men may be more sensitive to caffeine than women. We have to keep in mind the possible differences due to pharmacokinetic characteristics. We found no age effect on caffeine metabolite excretion, and age did not modify the expression of the acetylation phenotype in this population. However the effect of age on the acetylation phenotype appears controversial. Some authors $(11,23,24)$ showed no significant difference in the distribution of the acetylation phenotype according to age, whereas Gachalyi et al. (25) demonstrated that there were more slow acetylators amongst elderly Hungarians than in a younger population. Indeed, it is well known that the caffeine metabolism pathway shows maximal activity only during infancy (26). A recent review of $\mathrm{N}$ acetyltransferases (27) discusses the effect of age on. acetylation polymorphism. After considering many studies, the author concluded that there is a diminution of acetylating capacity with age but this is insufficient to modify the interpretation of a phenotype. However it is known that persons over 65 years have a different antimodal value for the separation of phenotypes and that children before 6 years can change their phenotype. These considerations justify the choice of our adult population with an age range of $18-63$ years.

Among the women, only 18 subjects took drugs (oestrogen and progestative drugs). These drugs did not 
change the distribution of the acetylator status and did not interfere with phenotyping or $\mathrm{N}$-acetyltransferase activity.

Tobacco did not influence the acetylation phenotype based on the 5-acetylamino-6-formylamino-3-methyluracil/1-methylxanthine ratio, and no correlation was observed between the excretions of the five major caffeine metabolites and tobacco consumption. We found a slight diminution of the quantity of unchanged caffeine (1,3,7-trimethylxanthine) among smokers compared with non-smokers and ex-smokers. The means (and SD) were respectively 6.23 (6.09), 10.53 (7.78), and $7.08(5.51) \mu \mathrm{mol} / 3 \mathrm{~h}$ with a F-value equal to $5.75(\mathrm{P}<0.025)$.

Arylamine chemicals in cigarette smoke have been implicated in the aetiology of some cancers $(28,29)$ and some diseases. There is some relationship between the acetylation phenotype and the risk of developing a disease or cancer. In the case of bladder cancer, Nhydroxymetabolites are formed by the action of cytochrome P-450 1A2, which is responsible for the 3demethylation of caffeine and the $\mathrm{N}$-oxidation of carcinogenic arylamines $(7,30)$. In contrast to tobacco, alcohol consumption seems to decrease the rate of 3-demethylation of caffeine.

The concentration of blood glucose was similar in the two phenotypes e.g. $5.33 \pm 0.498$ and $5.48 \pm 0.933$ $\mathrm{mmol} / \mathrm{l}$ respectively in slow and in rapid acetylators. We observed positive correlation with the 5 -acetylamino-6-formylamino-3-methyluracil/1-methylxanthine ratio in the slow acetylator group but not in the rapid acetylator group.

Indeed, in the rapid acetylators the glucose concentration was correlated with 5-acetylamino-6-formylamino-3-methyluracil, 1-methyluric acid and 1,3,7trimethylxanthine. Some authors have reported a relationship between the high frequency of rapid acetylators among diabetes mellitus type I subjects (31). Price Evans (27) in his very recent review reported that glucose accelerates the metabolism of acetylated compounds by increasing the concentration of acetylCoA.

The acetylation phenotype was assessed using the 5-acetylamino-6-formylamino-3-methyluracil/1-methylxanthine molar ratio. In this study, slow acetylators had a value lower than 0.85 . This first cut-off value is the optimal limit of separation between two Gaussian subpopulations; it was calculated by the iterative method of fuzzy-sets (17) and it differs slightly from that used in the literature $(6,7,8,16)$. The frequency of the allele controlling the slow acetylator phenotype was estimated to be 0.783 , giving $61.3 \%$ subjects classified as slow acetylators $(95 \%$ confidence interval
$53.4 \%$ to $69.2 \%$ ). This frequency of the allele controlling the slow acetylator phenotype is in agreement with those found in the literature for Caucasian populations $(6,8)$. The frequency distribution for the 5acetylamino-6-formylamino-3-methyluracil/1-methylxanthine ratio showed clearly two subgroups, and in the rapid acetylator group it showed the heterozygotes and the homozygotes for this codominant trait. This must be confirmed by a statistical pedigree analysis to ensure that the 6 subjects with a 5-acetylamino-6-formylamino-3-methyluracil/1-methylxanthine ratio value greater than 2.8 were true homozygous rapid acetylators. This result is in agreement with some other studies which identified three modes $(6,12,16)$. The present study identified clearly three distinct groups, the variabilities of which were quite different and particularly large in the rapid acetylator group.

The distribution of the 5-acetylamino-6-formylamino3-methyluracil/5-acetylamino-6-formylamino-3-methyluracil +1 -methylxanthine +1 -methyluric acid ratio seemed to be bimodal, but it does not enable the differentiation of the slow from the rapid acetylators. For the two other ratios, the observed frequencies for the allele controlling the slow acetylator phenotype were very close to that obtained with the use of the 5-acetylamino-6-formylamino-3-methyluracil/1-methylxanthine ratio for the acetylation phenotype determination. Pedigree analyses based on two metabolic caffeine ratios showed an agreement with a Mendelian segregation for 5-acetylamino-6-formylamino-3-methyluracil/1-methylxanthine and 5-acetylamino-6-formylamino-3-methyluracil/1-methylxanthine +1 methyluric acid $+1,7$-dimethylxanthine ratios. The 5-acetylamino-6-formylamino-3-methyluracil/1-methylxanthine +1 -methyluric acid +1 ,7-dimethyluric acid + 1,7-dimethylxanthine ratio should be discarded for the determination of the acetylation phenotype.

A few subjects were misclassified, implying that these two ratios can be employed for acetylator phenotype determination without misclassifying slow acetylators as fast acetylators.

The results support the idea that it could be useful in a Centre of Preventive Medicine to phenotype some patients in order to inform them about potential risks related to their acetylation phenotype. We found a allelic frequency of 0.783 for the allele controlling the slow acetylator phenotype. Age, sex, overweight (Que= telet index), environmental infliuences such as tobacco smoke, moderate alcohol intake and certain drugs do not affect the expression of the acetylation phenotype based on the 5-acetylamino-6-formylamino-3-methyl- 
uracil/1-methylxanthine ratio. The use of the 5-acetylamino-6-formylamino-3-methyluracil/1-methylxanthine +1 -methyluric acid $+1,7$-dimethyluric acid ratio to determine the acetylation phenotype, could be of interest for monitoring the acetylation phenotype obtained by the 5-acetylamino-6-formylamino-3-methyluracil/1-methylxanthine ratio, especially if the value is close to the cut-off value. This study validates the use of the 5-acetylamino-6-formylamino-3-methyluracil/1-methylxanthine ratio to determine the acetylation phenotype, i. e. the histogram was trimodal. With the exception of only 2 children, the offspring were also correctly phenotyped by this ratio.

\section{Acknowledgements}

We are indebted to Nestec S. A. (Nestlé, Research Department, Mr. Philippossian) and Dr. E. Rey (Hôpital Saint-Vincent de Paul, Service de Pharmacologie, Paris, France), who kindly provided the 5-acetylamino-6-formylamino-3-methyluracil. This work was partly supported in part by the Caisse Nationale d'Assurance Maladie des Travailleurs Salariés. We acknowledge I. Riché and H. F. Liu for their scientific help.

\section{References}

1. Ilett, K. F., David, B. M., Detchon, P., Castledenw, M. \& Kwa, R. (1987) Acetylation phenotype in colorectal carcinoma. Cancer Res. 47, 1466-1469.

2. Ladero, J. M., Jimenez, F. J., Benitez, J., Fernandez-Gundin, M. J., Martinez, C., Llerena, A., Cobaleda, J. \& Munoz, J. J. (1989) Acetylator polymorphisms in Parkinson's disease. Eur. J. Clin. Pharmacol. 37, 391-393.

3. Horai, Y. \& Ishizaki, T. (1988) N-acetylation polymorphisms of dapsone in a Japanese population. Br. J. Clin. Pharmacol. 25, 487-494.

4. Bozkurt, A., Basci, N. E., Tuncer, M. \& Kayaalq, S. O. (1990) $\mathrm{N}$-acetylation phenotyping with sulphadimidine in a Turkish population. Eur. J. Pharmacol. 38, 53-56.

5. Weber, W. W. \& Hein, D. W. (1985) N-acetylation pharmacogenetics. Pharmacol. Rev. 37, 25-79.

6. Kilbane, A. J., Silbart, L. K., Manis, M., Beitins, I. Z. \& Weber, W. W. (1990) Human N-acetylation genotype determination with urinary caffeine metabolites. Clin. Pharmacol. Ther. $46,470-477$.

7. Kadlubar, F. F., Talaska, G., Butler, M. A., Teitel, C. H., Massengill, J. P. \& Lang, N. P. (1990) Determination of carcinogenic arylamine $\mathrm{N}$-oxidation phenotype in humans by analysis of caffeine urinary metabolites. In: Metabolism Testing Methods and Chromosomes (Menselsohn, M. L. \& Albertini, R. J., eds.) Willy-Liss, pp. 107-114.

8. Hildebrand, M. \& Seifert, W. (1989) Determination of acetylator phenotype in Caucasians with caffeine. Eur. J. Clin. Pharmacol. 37, 525-526.

9. Evans, D. A. P. (1986) Acetylation. In. Ethnic Differences in Reactions to Drugs and Xenobiotics (Alan, R.) Liss Inc., pp. $209-242$.

10. Evans, D. A. P. \& White, T. A. (1984) Human acetylation polymorphism. J. Lab. Clin. Med. 63, 394-403.

11. Evans, D. A. P., Manley, K. A. \& McKunsick, V. A. (1960) Genetic control of isoniazid metabolism in man. Br. Med. J. 2, 485-491.

12. Grant, D. M., Tang, B. K. \& Kalow, W. (1984) A simple test for acetylator phenotype using caffeine. Br. J. Clin. Pharmacol. 17, 459-464.

13. Butler, M. A., Lang, N. P., Young, J. F., Caporaso, N. E., Vineis, P., Hayes, R. B., Teitel, C. H., Massengill, J. P., Lawsen, M. F. \& Kadlubar, F. F. (1992) Determination of CYP1A2 and NAT2 phenotypes in human populations by analysis of caffeine urinary metabolites. Pharmacogenetics 2, 116-127.

14. Grant, D. M., Morike, K., Eichelbaum, M. \& Meyer, B. A. (1990) Acetylation pharmacogenetics. The slow acetylator phenotype is caused by decreased or absent arylamine $\mathrm{N}$-acetyltransferase in huvian liver. J. Clin. Invest. 85, $968-$ 972.

15. Grant, D. M., Tang, B. K. \& Kalow, M. D. (1983) Variability in caffeine metabolism. Clin. Pharmacol. Ther. 33, $591-602$.
16. Grant, D. M., Tang, B. K. \& Kalow, W. (1983) Polymorphic $\mathrm{N}$-acetylation of caffeine metabolite. Clin. Pharmacol. Ther. 33, 355-359.

17. Schroeder, A. (1976) Analyse d'un mélange de distributions de probabilité de même type. Rev. Stat. Appl. 24, $1-39$.

18. Siest, G., Henny, J., Schiele, F. \& Young, D. S., eds. (1985) Interpretation of Clinical Laboratory Tests. Foster City, CA: Biochemical Publ.

19. Vincent-Viry, M., Riche, I., Rallet, A. \& Galteau, M. M. (1989) Test à la caféine, à la débrisoquine et au dextrométhorphane: étude de la conservation des urines. In: "Comptes Rendus du 7e Colloque de Pont-à-Mousson, Biologie Prospective" (Galteau, M. M., Henny, J. \& Siest, G., eds.) 4-9 Octobre 1989, Paris, Ed. John Libbey Eurotext, pp. $831-836$.

20. Vincent-Viry, M., Braz Vieira da Silva Pontes, Z., Gueguen, R., Galteau, M. M. \& Siest, G. (1992) Human acetylation phenotype can be assessed by at least two caffeine metabolite ratios: A familial study. Submitted for publication.

21. Blum, M., Grant, D. M., McBridge, W., Heim, M. \& Meyer, U. A. (1990) Human arylamine $\mathrm{N}$-acetyltransferase genes: isolation chromosomal localization and functional expression. DNA and Cell Biol. 9, 193-203.

22. Griffiths, R. R., Evans, S. M., Heishman, S. J., Preston, K. L., Sannerud, C. A., Wolf, B. \& Woodson, P. P. (1985) Low-dose caffeine discrimination in humans. J. Pharmacol. Exp. Ther. 252. 970-978.

23. Philip, P. A., Gaued, S. L., Rogers, H. J. \& Crome, P. (1987) Influence of age, sex and body weight on the dapsone acetylation phenotype. Eur. J. Clin. Pharmacol. 23, 709713.

24. Farah, F., Taylor, W., Rawlins, M. D. \& James, O. (1977) Hepatic drug acetylation and oxidation: effects of aging in man. Br. Med. J. 2, 155-156.

25. Gachalyi, B., Vas, A., Hajos, P. \& Kaldor, A. (1984) Acetylator phenotype: effect of age. Eur. J. Clin. Pharmacol. 26. $43-45$.

26. Pons, G., Carrier, O., Richard, M. O., Rey, E., d'Athis, P., Moran, C., Badoual, J. \& Olive, G. (1988) Developmental changes of caffeine elimination in infancy. Dev. Pharmacol. Ther. $11,258-264$.

27. Price Evans, D. A. (1992) N-acetyltransferase. In: Pharmacogenetics of Drug Metabolism (Kalow, W., ed.) Pergamon Press. Inc. (New York), pp. 95-178.

28. Flammang, T. J., Yamazoe, Y., Guengerich, F. P. \& Kadlubar, F. F. (1987) The 5-acetyl coenzyme A-dependent metabolic activation of the carcinogen N-hydroxy-2-aminofluorene by human liver cytosol and its relationship to the aromatic amine $\mathrm{N}$-acetyltransferase phonotype. Carcinogenesis $8,1967-1970$. 
29. Vineis, P., Caporaso, N., Tannenbaum, S. R., Skipper, P. L., Glogowiki, J., Bartsch, H., Coda, M., Talaska, G. \& Kadlubar, F. F. (1990) Acetylation phenotype, carcinogenhemoglobin adducts and cigarette smoking. Cancer Res. 50, 3002-3004.

30. Butler, M. A., Iwasaki, M., Guengerich, F. P. \& Kadlubar, F. F. (1989) Human cytochrome P-450PA (P-450 IA2), the phenacetin $\mathrm{O}$-deethylase, is primarily responsible for the hepatic 3-demethylation of caffeine and N-oxidation of carcinogenic arylamines. Proc. Natl. Acad. Sci. USA 86, 7696-7700.
31. Bechtel, Y. C., Joanne, C., Grandmottet, M. \& Bechtel, P. R. (1988) The influence of insulin-dependent diabetes on the metabolism of caffeine and the expression of the debrisoquin oxidation phenotype. Clin. Pharmacol. Ther. 44, $408-417$.

Professor M. M. Galteau

Laboratoire du Centre de Médecine Préventive

2 Avenue du Doyen Jacques Parisot

F-54500 Vandœuvre-les-Nancy

France 